\title{
TECNOLOGIA DE APLICAÇÃO DE TRICHODERMA SP. E INTERFERÊNCIA NA FITOSSOCIOLOGIA DE PLANTAS DANINHAS NA CULTURA DA MANDIOCA
}

\author{
ITALLO MICHAEL SOARES LEAL, \\ LEANDRO DO ROSARIO SILVA, \\ GISELE BARATA DA SILVA, \\ GABRIEL DAMASCENO FERREIRA CUNHA, \\ MAURA GABRIELA DA SILVA BROCHADO, \\ GABRIEL DA SILVA VASCONCELOS, \\ ANA CLARA MOURA DE SOUSA, \\ ANA CAROLINA MELO RIBEIRO, \\ ALEXANDRA MONTEIRO ALVES, \\ RAFAEL GOMES VIANA.
}

\begin{abstract}
RESUMO - A cultura da mandioca possui grande importância para as populações principalmente aquelas em desenvolvimento, por ser uma cultura com alta rusticidade e produtividade. O uso do microrganismo Trichoderma sp. em culturas agrícolas pode reduzir a incidência de doenças, pragas e promover crescimento da cultura. No entanto, pode promover também maior ocorrência de plantas daninhas. Objetivou-se com este trabalho, avaliar a influência da tecnologia de aplicação de Trichoderma sp. na fitossociologia de plantas daninhas na cultura da mandioca. Foi realizado a aplicação de Trichoderma sp. com três tipos de aplicação (área total, faixa e localizada) e quatro volumes de calda (50;100; 200 e $400 \mathrm{~L} \mathrm{ha}^{-1}$ ) e mais uma testemunha sem aplicação e sem capina em um delineamento em blocos casualizados com quatro repetições. As espécies foram coletadas, identificadas e calculados os parâmetros fitossociologicos. Foram identificadas 24 espécies distribuídas em 8 famílias botânicas. As famílias mais representativas foram: Poaceae, Cyperaceae e Fabaceae. A espécie Paspalum Maritimum apresentou o maior índice de valor de importância e esteve presente em todas as parcelas. Ao comparar o modo de aplicação com diferentes volumes de calda observou-se crescimento linear na densidade de plantas daninhas com o incremento no volume de calda quando utilizado a aplicação em área total e na aplicação em faixa, há comportamento de crescimento quadrático da densidade, já na aplicação localizada teve leve redução na densidade de plantas daninhas com o aumento no volume de calda. O modo de aplicação e o volume de calda de Trichoderma sp. mudam a dinâmica de plantas daninhas na cultura da mandioca.
\end{abstract}

PALAVRAS-CHAVE - Microrganismo promotor de crescimento; Pontas de pulverização; Manihot esculenta.

\section{INTRODUÇÃO}

A cultura da Mandioca (Manihot esculenta crantz), originária da América do sul, com raízes tuberosas ricas em amido [3], é amplamente produzida em várias regiões do Brasil tendo um papel importante como principal fonte de carboidrato para milhões de pessoas de acordo com a Organização das Nações Unidas para agricultura e alimentação [14]. Além de ter uma importante participação na geração de emprego e de renda, especialmente para pequenos e médios produtores [28]. O que ressalta a importância dessa cultura para o agronegócio mundial.

Apesar da cultura da mandioca apresentar um alto poten- cial produtivo, sendo alcançado em algumas regiões, produtividade superior a 20 toneladas por hectare, a produtividade nacional ainda é baixa [18]. Um dos fatores que mais vem contribuído para baixa produtividade da cultura é o manejo inadequado das plantas daninhas [1]. A interferência de plantas daninhas na mandioca pode provocar decréscimo na produtividade, com relatos de perdas de até $90 \%$, quando não controlada de maneira adequada ( [10]; [23]).

Outro fator de perda de produção é a ocorrência de doenças tais como: antracnose, super alongamento e podridões radiculares [31], porém, a podridão radicular se destaca por afetar diretamente o desenvolvimento da planta e o produto 
de comercialização [22].

Uma das maneiras de se controlar patógenos e ainda promover aumento de produtividade em mandioca foi observado por [30], utilizando isolados de Trichoderma sp. inoculados em plantas no campo. O mecanismo de promoção de crescimento vegetal ocasionada por Trichoderma sp. pode envolver alguns fatores ainda poucos esclarecidos, como a produção de hormônios e vitaminas, a solubilização de fosfatos e controle de patógenos [20]. Nessa circunstância, os fungos do gênero Trichoderma sp. possuem destacada importância pela diversidade e capacidade de adaptação em diferentes ambientes além de apresentar diferentes mecanismos de ação [25].

Uma característica observada por produtores rurais que utilizam o Trichoderma sp. na cultura da mandioca, é que há maior ocorrência de plantas daninhas no plantio alguns dias após a aplicação do microrganismo. Ressalta-se que também é uma dúvida se há relação entre a ocorrência das plantas daninhas com a tecnologia de aplicação empregada. A tecnologia de aplicação visa a deposição do produto biologicamente ativo sobre o alvo, empregando todo conhecimento necessário e suas interações com o ambiente de maneira que seja econômica, ambientalmente segura e com a máxima eficiência [24]. Ademais o conhecimento da localização do alvo da aplicação é imprescindível na aplicação do produto e na escolha da técnica mais adequada para a pulverização [4]. Características técnicas de pontas de pulverização, tais como: vazão, perfil de distribuição, volume de calda, tamanho de gota, cobertura do alvo e o tipo de aplicação interferem diretamente na eficiência do produto aplicado [31].

Pelo exposto, objetivou-se com este trabalho, avaliar a influência da tecnologia de aplicação de Trichoderma sp. na fitossociologia de plantas daninhas na cultura da mandioca.

\section{MATERIAL E MÉTODOS}

\section{A. LOCALIZAÇÃO E CARACTERIZAÇÃO DA ÁREA}

$O$ experimento foi realizado no campo experimental da Fazenda Escola de Castanhal-PA, da Universidade Federal Rural da Amazônia (Figura 1).

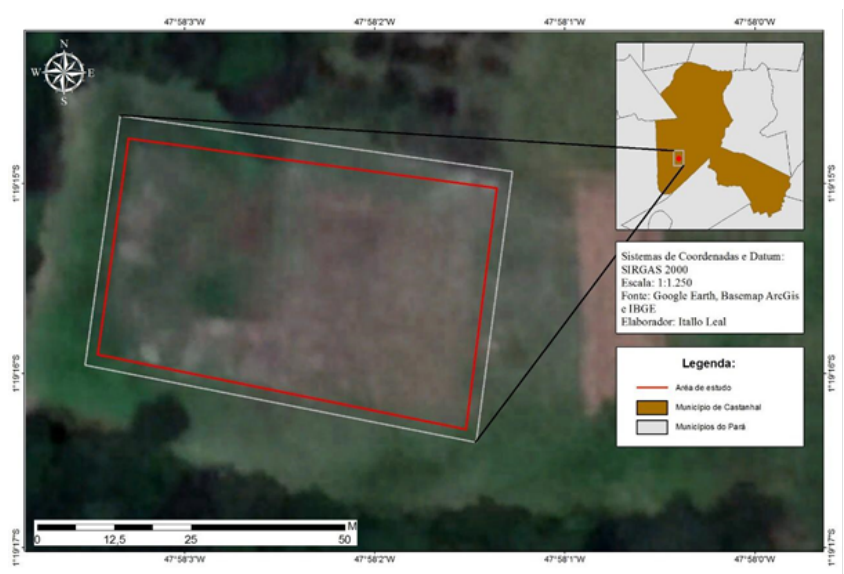

Figura 1. localização da área em estudo. Fonte: Autor 2019.
Castanhal tem um clima tropical e uma pluviosidade significativa ao decorrer do ano mesmo em meses mais seco. O clima de acordo com a classificação de Köppen e Geiger é o af. As temperaturas médias anuais são de $26.5^{\circ} \mathrm{C}$ e a pluviosidade média anual de $2432 \mathrm{~mm}$. O mês mais seco é novembro com $63 \mathrm{~mm}$ e o mês de março é o mês com maior precipitação, apresentando uma média de $411 \mathrm{~mm}$. Quando comparados o mês mais seco tem uma diferença de precipitação de $348 \mathrm{~mm}$ em relação ao mês mais chuvoso. As temperaturas médias têm uma variação de $1.2{ }^{\circ} \mathrm{C}$ durante o ano [10].

\section{B. CARACTERIZAÇÃO DO SOLO}

$\mathrm{O}$ solo da área foi classificado de ocorrência de latossolo amarelo, com base em unidade de mapeamento da Embrapa Amazônia Oriental, e apresenta as seguintes características físico-químicas (Tabela 1).

Tabela 1. Análise química do solo da área experimental.

\begin{tabular}{|c|c|c|c|c|c|c|c|c|}
\hline Prof. & $\mathrm{K}$ & $\mathrm{Na}$ & $\mathrm{P}$ & $\mathrm{Al}$ & $\mathrm{Ca}$ & $\begin{array}{c}\mathrm{Ca}+ \\
\mathrm{Mg}\end{array}$ & $\begin{array}{c}\mathrm{H}+ \\
\mathrm{Al}\end{array}$ & $\begin{array}{l}\mathrm{pH} . \\
\text { Água }\end{array}$ \\
\hline$(\mathrm{cm})$ & \multicolumn{3}{|c|}{$-\mathrm{mg} / \mathrm{dm}^{3}-$} & \multicolumn{4}{|c|}{$-\mathrm{cmolc} / \mathrm{dm}^{3}-$} & \\
\hline $0-20$ & 23 & 10 & 81 & 0,2 & 1,9 & 2,4 & 3,77 & 3,7 \\
\hline
\end{tabular}

\section{IMPLANTAÇÃO E DESENVOLVIMENTO DO PLANTIO.}

A área foi preparada em sistema convencional com duas arações e uma gradagem niveladora. De acordo com a análise do solo (Tabela 1) não foi necessário realizar calagem e adubação fosfatada, apenas adubação potássica com aplicação de cloreto de potássio $\left(100 \mathrm{~kg} \mathrm{ha}^{-1}\right)$ e nitrogenada com uréia (89 $\mathrm{kg} \mathrm{ha}^{-1}$ ) parcelados aos 30, 70 e 110 dias após o plantio (DAP). O plantio de mandioca, cultivar BRS Poti, foi realizado com o uso de plantadeira mecanizada no espaçamento entre linhas de $0,9 \mathrm{~m}$ e aproximadamente $1,0 \mathrm{~m}$ entre plantas, promovendo densidade aproximada de 11.111 plantas ha ${ }^{-1}$.

$\mathrm{O}$ delineamento experimental foi de blocos ao acaso, em arranjo fatorial $4 \times 3+1$, sendo quatro volumes de calda com Trichoderma (50, 100, 200 e $\left.400 \mathrm{~L} \mathrm{ha}^{-1}\right)$, três modos de aplicação (área total, faixa e localizado) e uma testemunha sem aplicação de Trichoderma e sem capina, correspondendo a 13 tratamentos com 4 repetições. Os blocos tinham dimensões de 4 x 5 m, excluindo-se da análise um metro de bordadura, sendo utilizado como área útil os $12 \mathrm{~m}^{2}$ centrais.

Os modos de aplicação foram determinados de acordo com as características técnicas de três modelos de pontas de pulverização, os quais estão descritos na (Tabela 2) e aplicados de acordo com o esquema da Figura 2.

Os volumes de calda para cada ponta de pulverização foram alcançados com a variação de vazão de cada ponta, conforme descrito na tabela 3 , com o uso de um pulverizador pressurizado a $\mathrm{CO} 2$, com pressão constante de $50 \mathrm{lib} \mathrm{pol}^{-2} \mathrm{e}$ velocidade aproximada de $4 \mathrm{~km} \mathrm{~h}^{-1}$. 
Tabela 2. Características técnicas das pontas de pulverização utilizadas na aplicação de Trichoderma.

\begin{tabular}{|c|c|c|c|}
\hline & \multicolumn{3}{|c|}{ Tipo de aplicação } \\
\hline & Área total & Faixa & Localizada \\
\hline \multirow[b]{2}{*}{ Ponta de pulverização } & STIA & PBIA & MJ6 \\
\hline & & & \\
\hline Ângulo de abertura & $\sum_{130^{\circ}}$ & $60^{\circ}$ & $45^{\circ}$ \\
\hline Formato do jato & 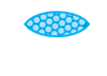 & 8 & $\begin{array}{l}0^{\circ} \bullet \\
\bullet_{0}^{\circ}\end{array}$ \\
\hline
\end{tabular}

Fonte: MagnoJet, com adaptação (2016).
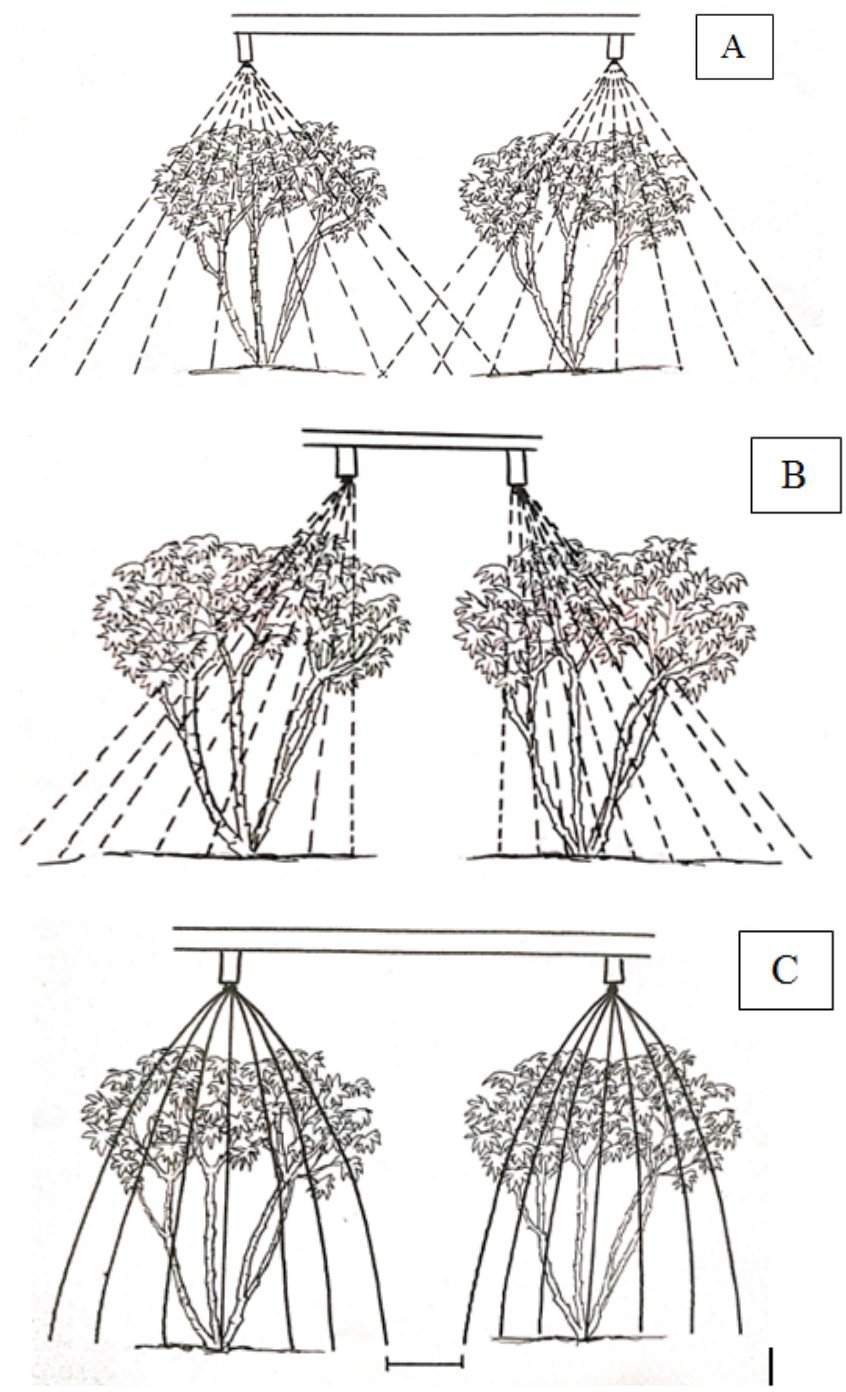

Figura 2. Formato do jato em aplicações em: área total (A); faixa (B) e localizada (C) Fonte: Autor 2019.

A dose de microrganismo foi de $2 \mathrm{~kg}$ de formulação de Trichoderma sp. inoculado em arroz ha ${ }^{-1}$, aplicados aos 15
Tabela 3. Descrição do volume de calda pulverizado e a ponta de pulverização correspondente.

\begin{tabular}{|c|c|c|}
\hline Tipo de aplicação & $\begin{array}{c}\text { Volume de } \\
\text { calda (L ha-1) }\end{array}$ & $\begin{array}{c}\text { Ponta } \\
\text { de pulverização }\end{array}$ \\
\hline \multirow{4}{*}{ Área total } & 50 & ST-IA 11005 \\
\cline { 2 - 3 } & 100 & ST-IA 11001 \\
\cline { 2 - 3 } & 200 & ST-IA 11002 \\
\cline { 2 - 3 } Faixa & 400 & ST-IA 11004 (2X) \\
\hline \multirow{4}{*}{ Localizada } & 50 & PB-IA 8001 \\
\cline { 2 - 3 } & 100 & PB-IA 8002 \\
\cline { 2 - 3 } & 200 & PB-IA 8004 \\
\cline { 2 - 3 } & 400 & PB-IA8004 (2X) \\
\cline { 2 - 3 } & 50 & MJ6 015 \\
\cline { 2 - 3 } & 100 & MJ6 02 \\
\hline \multirow{4}{*}{} & 200 & MJ6 04 \\
\hline
\end{tabular}

e 30 dias após o plantio.

\section{PRODUÇÃO DE TRICHODERMA SP.}

Os fungos do gênero Trichoderma foram obtidos de amostras de solo coletadas na Fazenda Reunida Sococo, localizada no município de Santa Izabel do Pará. As amostras foram levadas ao Laboratório de Proteção de Plantas da Universidade Federal Rural da Amazônia, para que pudesse ser feita a diluição seriada. Para isso foram retiradas $10 \mathrm{~g}$ de solo de cada amostra e em seguida transferida para frascos de 250 $\mathrm{mL}$, ao qual se adicionaram $90 \mathrm{~mL}$ de água destilada.

Após agitação por 40 minutos a $114 \mathrm{rpm}$, alíquotas de 1 $\mathrm{mL}$ dessas suspensões foram transferidas para outros tubos, procedendo-se as diluições seriadas em água destilada esterilizada. Para o isolamento, alíquotas de $100 \mu \mathrm{L}$ das diluições seriadas de $10^{-2}$ e $10^{-3} \mathrm{~g}$ de solo/mL de água adicionadas em placas de Petri contendo o meio de cultura BDA (BatataDextrose-Ágar), as placas foram mantidas em bancada com temperatura ambiente. Após sete dias, colônias típicas de Trichoderma foram transferidas para meio BDA e mantidas a $28{ }^{\circ} \mathrm{C}$, com fotoperíodo de 12 horas, para obtenção das culturas puras. As colônias foram identificadas e preservadas.

Posteriormente foi acrescentado em grão de arroz, micélio dos isolados de Trichoderma sp. os quais permaneceram em câmara climatizada a $22{ }^{\circ} \mathrm{C}$ com fotoperíodo de $12 \mathrm{~h}$ por 15 dias para a colonização completa dos grãos de arroz. Para serem utilizados nos ensaios os grãos já colonizados com Trichoderma sp. [6 $610^{8}$ conídios $\left.\mathrm{mL}^{-1}\right]$ foram secos na estufa por $48 \mathrm{~h}$ em temperatura constante de $37^{\circ} \mathrm{C}$ e em seguida armazenados sob refrigeração a $4^{\circ} \mathrm{C}[32]$.

No preparo da calda foi realizado a lavagem dos grãos de arroz com água destilada, sobre uma gaze esterilizada imersa em um funil. O líquido coado foi acondicionado em garrafas PET de 2 L previamente lavadas e secas. A calda foi preparada no dia da aplicação. As aplicações foram realizadas aos 30 e 75 dias após a emergência das plantas de mandioca, no período da manhã. 


\section{E. FITOSSOCIOLOGIA.}

A fitossociologia de plantas daninhas foi realizada 15 dias após a aplicação da segunda dose de Trichoderma sp. Para o estudo, utilizou-se o método do quadrado inventário $(0,5 \mathrm{x}$ $0,5 \mathrm{~m}$ ), lançado ao acaso $1 \mathrm{vez}$ em cada bloco, totalizando 4 repetições e $1,0 \mathrm{~m}^{2}$ de área por tratamento. A cada lançamento, foi coletada a parte aérea das espécies encontradas dentro do quadrado e devidamente identificadas e cadastradas, sendo obtido o número de indivíduos por espécie.

Para análise das comunidades das espécies presentes, foram calculados os parâmetros fitossociológicos: frequência - permite avaliar a distribuição das espécies nas parcelas; densidade - quantidade de plantas de cada espécie por unidade de área; abundância - informa sobre a concentração das espécies na área; frequência relativa, densidade relativa e abundância relativa - informam a relação de cada espécie com as outras espécies encontradas na área; e índice de valor de importância - indica quais espécies são mais importantes dentro da área estudada.

No cálculo dessas características foram utilizadas as fórmulas que se seguem [25]:

$$
\begin{gathered}
\text { Frequncia }(\text { Fre })=\frac{\mathrm{N}^{\circ} \text { de parcelas que contêm o indivíduo }}{\mathrm{N}^{\circ} \text { total de parcelas utilizadas }} \\
\text { Densidade }(\text { Den })=\frac{\mathrm{N}^{\circ} \text { total de indivíduos por espécie }}{\text { Área total amostrada }}
\end{gathered}
$$$$
\text { Abundncia }(A b u)=\frac{\mathrm{N}^{\circ} \text { total de indivíduos por espécie }}{\mathrm{N}^{\circ} \text { total de parcelas que contêm a espécie }}
$$

Frequnciarelativa $($ Frr $)=\frac{\text { Frequência da espécie x100 }}{\text { Frequência total de todas as espécies }}$

$$
\text { Densidaderelativa }(\text { Der })=\frac{\text { Densidade da espécie } \mathrm{x} 100}{\text { Densidade total das espécies }}
$$

Abundnciarelativa $(A b r)=\frac{\text { Abundância da espécie } \mathrm{x} 100}{\text { Abundância total de todas as espécies }}$

Índice de Valor de Importância (IVI) = Frr + Der + Abr

\section{F. MASSA SECA DE PARTE AÉREA DE PLANTAS DANINHAS.}

Após a identificação das plantas daninhas, foi realizada a secagem da parte aérea com o acondicionamento em sacos de papel e secagem em estufa de circulação forçada de ar por $72 \mathrm{~h} \mathrm{a} \pm 60{ }^{\circ} \mathrm{C}$ de temperatura. A mensuração de peso foi feita em balança de precisão até a segunda casa centesimal

\section{G. ANÁLISE ESTATIÍSTICA.}

Para os parâmetros de volume de calda estudou-se a resposta por modelo regressão de que melhor explicasse o fenômeno biológico de densidade, frequência, abundância e massa seca. A comparação entres os modos de aplicação foi feita por análise de variância e em caso de significância foi feita a comparação pelo teste de Tukey a 5\% de probabilidade.

A análise fitossociológica foi feita por descrição e análise biológica dos parâmetros.

\section{RESULTADOS E DISCUSSÃO \\ A. FITOSSOCIOLOGIA GERAL.}

Observou-se a ocorrência de 24 espécies de plantas daninhas, distribuídas em oito famílias botânicas Poaceae, Cyperaceae, Fabaceae, Euphorbiaceae, Cleomaceae, Asteraceae, Loganiaceae e Aráceae conforme observado na tabela 4. Destacase a grande ocorrência de plantas daninhas das famílias Cyperaceae e Poaceae, com 7 e 8 famílias respectivamente, ambas com alto potencial de propagação tanto por via vegetativa quanto seminífera, estão entre as principais famílias de plantas daninhas encontradas frequentemente em diferentes culturas exploradas no Brasil [26]. Sendo frequente o uso de implementos de revolvimento do solo em produção de mandioca, é um fator que propicia a disseminação e aumento populacional de plantas com essa característica, já que a prática promove o corte e enterrio das plantas daninhas. Resultados similares foram encontrados por [20].

Ao observar o número total de indivíduos NTI (Tabela 4), a espécie que teve maior representatividade foi a Paspalum maritimum (1463), seguido da Pennisetum purpureum (195), e consequentemente maior índice de valor de importância IVI. Ambas da família Poaceae, de acordo com [18] ambas possuem reprodução assexuadas (rizoma) e sexuadas (sementes) com grande capacidade de produção de massa seca em condições favoráveis de radiação solar, temperatura do ar e disponibilidade de água. Segundo [5] a mandioca possui um crescimento lento, o que promove a exposição do solo à radiação solar por um período prolongado, possibilitando o crescimento e desenvolvimento de plantas daninhas com essas características.

Uma característica preocupante de ocorrência de Paspalum maritimum é a possibilidade de efeito deletério a cultura da mandioca por efeito alelopático. [28] observou efeito alelopático de extratos de Paspalum maritimum no desenvolvimento de: Mimosa pudica, Senna obtusifolia, Brachiaria brizantha cv. Marandu e Pueraria phaseoloides.

A espécie Cleome aculeata (Tabela 4) ficou entre as três espécies com maior NTI. Essa espécie tem como característica ter elevada rusticidade crescendo mesmo em solos de baixa fertilidade, em afloramentos rochosos, campos rupestres, áreas brejosas e orlas de florestas [6]. Além disso, [14] cita que Cleome aculeata é uma hospedeira alternativa do nematoide das galhas da espécie Meloidogyne incognita no estado do Pará. O principal mecanismo de dispersão são as sementes. [16] observaram a ocorrência de espécies do gênero Cleome no banco de sementes de uma área de caatinga no Nordeste Brasileiro. O manejo da espécie visando a redução de dispersão e de potencial dano por hospedeiro alternativo de nematoides é o controle em pós-emergência antes da floração e o uso de herbicidas pré-emergentes para reduzir a emergência de sementes. 
Tabela 4. Espécies de plantas daninhas dentro de cada família encontrada na cultura da mandioca e suas respectivas características fitossociológicas.

\begin{tabular}{|c|c|c|c|c|c|c|c|c|c|}
\hline ESPÉCIES & NTI & NPP & DEN & FRE & ABU & DER & FRR & ABR & IVI \\
\hline \multicolumn{10}{|c|}{ Cyperneae } \\
\hline Cypense distans & 8 & 3 & 0,05 & 0,57 & 2,67 & 2,22 & 0,37 & 1,47 & 4,06 \\
\hline Cypenzs aggreganes & 31 & 11 & 0,20 & 2,21 & 2,82 & 8,15 & 1,43 & 1,55 & 11,13 \\
\hline Cypens suinduensis & 10 & 3 & 0,05 & 0,71 & 3,33 & 2,22 & 0,46 & 1,83 & 4,52 \\
\hline Cypens flaves & 1 & 1 & 0,02 & 0,07 & 1,00 & 0,74 & 0,05 & 0,55 & 1,34 \\
\hline cypers inia & 2 & 2 & 0,04 & 0,14 & 1,00 & 1,48 & 0,09 & 0,55 & 2,12 \\
\hline Kydlinga odorata & 65 & 2 & $\mathbf{0 , 0 4}$ & 4,64 & 32,50 & 1,48 & 3,00 & 17,87 & 22,35 \\
\hline Kyllinga brevifolia & 15 & 3 & 0,05 & 1,07 & 5,00 & 2,22 & 0,69 & 2,75 & 5,66 \\
\hline \multicolumn{10}{|c|}{ Panceae } \\
\hline Paspohos mopitines & 1463 & 40 & 0,71 & 104,50 & 36,58 & 29,63 & 67,48 & 20,11 & 117,22 \\
\hline Penuisetum pupeneus & 195 & 8 & 0,14 & 13,93 & 24,38 & 5,93 & 8,99 & 13,40 & 28,32 \\
\hline Eragrostis plown & 98 & 11 & 0,20 & 7,00 & 8,91 & 8,15 & 4,52 & 4,90 & 17,57 \\
\hline Eleusine indica & 56 & 3 & 0,05 & 4,00 & 18,67 & 2,22 & 2,58 & 10,26 & 15,07 \\
\hline Cymodon daxtylon & 42 & 6 & $\mathbf{0 , 1 1}$ & 3,00 & 7,00 & 4,44 & 1,94 & 3,85 & 10,23 \\
\hline Digitoria bicornis & 56 & 3 & 0,05 & 4,00 & 18,67 & 2,22 & 2,58 & 10,26 & 15,07 \\
\hline Brachioria neiziensis & 1 & $\mathbf{1}$ & 0,02 & 0,07 & 1,00 & 0,74 & 0,05 & 0,55 & 1,34 \\
\hline Brachioria subquadripora & 1 & 1 & 0,02 & 0,07 & 1,00 & 0,74 & 0,05 & 0,55 & 1,34 \\
\hline \multicolumn{10}{|c|}{ Enplentbinceae } \\
\hline Sebastionia corriculata & $\mathbf{1}$ & $\mathbf{1}$ & 0,02 & 0,07 & 100 & 0,74 & 0,05 & 0,55 & 1,34 \\
\hline Croton lobahes & 1 & 1 & 0,02 & 0,07 & 1,00 & 0,74 & 0,05 & 0,55 & 1,34 \\
\hline \multicolumn{10}{|c|}{ Clennmeae } \\
\hline Cleome aculeata & 105 & 25 & 0,45 & 7,50 & 4,20 & 18,52 & 4,84 & 2,31 & 25,67 \\
\hline \multicolumn{10}{|c|}{ Asternceae } \\
\hline Enifia coccinea & 1 & 1 & 0,02 & 0,07 & 1,00 & 0,74 & 0,05 & 0,55 & 1,34 \\
\hline \multicolumn{10}{|c|}{ Legminceae } \\
\hline Spigela onthefia & 5 & 3 & 0,05 & 0,36 & 1,67 & 2,22 & 0,23 & 0,92 & 3,37 \\
\hline \multicolumn{10}{|c|}{ Flhaceae } \\
\hline Semun obhuseaforea & 2 & $\mathbf{1}$ & 0,02 & 0,14 & 2,00 & 0,74 & 0,09 & 1,10 & 1,93 \\
\hline Desmodium uncinatum & 4 & $\mathbf{1}$ & 0,02 & 0,29 & 4,00 & 0,74 & 0,18 & 2,20 & 3,12 \\
\hline Mímosa pudica & 3 & 2 & $\mathbf{0 , 0 4}$ & 0,21 & 1,50 & 1,48 & 0,14 & 0,82 & 2,44 \\
\hline \multicolumn{10}{|c|}{ Ariceae } \\
\hline Coladium bicolor & 2 & 2 & $\mathbf{0 , 0 4}$ & 0,14 & 1,00 & 1,48 & 0,09 & 0,55 & 2,12 \\
\hline TOTAL & 2168 & 135 & 2,41 & 154,86 & 181,88 & 100,00 & 100,00 & 100,00 & 300,00 \\
\hline
\end{tabular}

$\mathrm{NTI}=$ número total de indivíduos, $\mathrm{NPP}=$ número de parcelas presentes, $\mathrm{DEN}=$ densidade, $\mathrm{FRE}=$ frequiência, $\mathrm{ABU}=$ abundância, $\mathrm{DER}=$ densidade relativa, $\mathrm{FRR}=$ freqüência relativa, $\mathrm{ABR}=$ abundância relativa e IVI = índice de valor de importância.

Como foi frequente a ocorrência de espécies monocotiledôneas (Tabela 4), e estas apresentam alta relação carbono nitrogênio, é possível o uso dessas plantas como cobertura morta em plantio direto, reduzindo assim os possíveis danos de ocorrência de plantas daninhas proporcionados pelo plantio convencional. [15] observaram que em plantio direto há menor ocorrência de plantas daninhas em comparação ao preparo convencional, desta forma promovendo menor impacto ao ambiente devido à redução do uso de herbicidas. [8] observaram que plantas daninhas com alta relação carbono nitrogênio podem ser usadas como cobertura do solo. Além disso, o uso de Poaceas como plantas de cobertura é importante para a absorção de nutrientes, especialmente do potássio, de camadas subsuperficiais e disponibilização na superfície do solo [7].

\section{B. COMPARAÇÃO DE FITOSSOCIOLOGIA ENTRE OS TRATAMENTOS}

Quando comparado os modos de aplicação observou-se que a aplicação em área total com volume de calda de $400 \mathrm{~L}$ $\mathrm{ha}^{-1}$ e $200 \mathrm{~L} \mathrm{ha}^{-1}$, ocorreu um maior número de espécies daninhas encontradas, 10 e 8 respectivamente (tabela 5), seguido da aplicação em faixa com volume de calda de 50 $\mathrm{L} \mathrm{ha}^{-1}$, quando comparado com a testemunha estes tiveram um número de espécies maior. Isto pode ser justificado pelo fato de que ocorreu uma maior dispersão do microrganismo na área, favorecendo assim uma maior disponibilidade do microrganismo promotor de crescimento para as plantas daninhas.

Conforme Tabela 5, onde NTI = número total de indivíduos, $\mathrm{NPP}=$ número de parcelas presentes, $\mathrm{DEN}=$ densidade, $\mathrm{FRE}=$ frequência, $\mathrm{ABU}=$ abundância, $\mathrm{DER}=$ densi- 
dade relativa, $\mathrm{FRR}=$ frequência relativa, $\mathrm{ABR}=$ abundância relativa e IVI = índice de valor de importância.

Tabela 5: Análise fitossociológica de plantas daninhas em diferentes tipos de aplicação (faixa, localizada e área total) e diferentes volumes de calda (50, 100, 200 e $\left.400 \mathrm{~L} \mathrm{ha}^{-1}\right)$ de Trichoderma sp.

\begin{tabular}{|c|c|c|c|c|c|c|c|c|c|c|c|}
\hline $\begin{array}{l}\text { Tipo de aplica- } \\
\text { ção }\end{array}$ & $\begin{array}{ll}\begin{array}{l}\text { Volume } \\
\text { calda } \\
\text { ha-1) }\end{array} & \text { de } \\
\end{array}$ & Espécie & NTI & NPP & FRE & DEN & $\overline{\mathbf{A B U}}$ & FRE & CDER & ABR & IVI \\
\hline \multirow{45}{*}{ Área total } & \multirow{6}{*}{50} & Paspalum maritimum & 90 & 3 & 0,75 & 90 & 30 & 33 & 84 & 75 & 192 \\
\hline & & $\begin{array}{l}\text { Brachiaria } \\
\text { subquadripara }\end{array}$ & 1 & 1 & 0,25 & 1 & 1 & 11 & 1 & 3 & 15 \\
\hline & & Cyperus aggregatus & 12 & 2 & 0,5 & 12 & 6 & 22 & 11 & 15 & 48 \\
\hline & & Cleome aculeata & 2 & 1 & 0,25 & 2 & 2 & 11 & 2 & 5 & 18 \\
\hline & & Cyperus iria & 2 & 2 & 0,5 & 2 & 1 & 22 & 2 & 3 & 27 \\
\hline & & TOTAL & 107 & 9 & 2,25 & 107 & 40 & 100 & 100 & 100 & 300 \\
\hline & \multirow{7}{*}{100} & Paspalum maritimum & 118 & 4 & 1 & 118 & 29,5 & 36 & 78 & 55 & 169 \\
\hline & & Eragrostis plana & 4 & 2 & 0,5 & 4 & 2 & 18 & 3 & 4 & 25 \\
\hline & & Eleusine indica & 10 & 1 & 0,25 & 10 & 10 & 9 & 7 & 19 & 34 \\
\hline & & Cleome aculeata & 15 & 2 & 0,5 & 15 & 7,5 & 18 & 10 & 14 & 42 \\
\hline & & Cyperus surinamensis & 1 & 1 & 0,25 & 1 & 1 & 9 & 1 & 2 & 12 \\
\hline & & Kyllinga brevifolia & 4 & 1 & 0,25 & 4 & 4 & 9 & 3 & 7 & 19 \\
\hline & & TOTAL & 152 & 11 & 2,75 & 152 & 54 & 100 & 100 & 100 & 300 \\
\hline & \multirow{9}{*}{200} & Mimosa pudica & 2 & 1 & 0,25 & 2 & 2 & 8 & 1 & 2 & 12 \\
\hline & & Paspalum maritimum & 98 & 4 & 1 & 98 & 24,5 & 33 & 57 & 28 & 118 \\
\hline & & Cleome aculeata & 24 & 2 & 0,5 & 24 & 12 & 17 & 14 & 14 & 44 \\
\hline & & Spigelia anthelmia & 1 & 1 & 0,25 & 1 & 1 & 8 & 1 & 1 & 10 \\
\hline & & Eragrostis plana & 1 & 1 & 0,25 & 1 & 1 & 8 & 1 & 1 & 10 \\
\hline & & Coladium bicolor & 1 & 1 & 0,25 & 1 & 1 & 8 & 1 & 1 & 10 \\
\hline & & Eleusine indica & 45 & 1 & 0,25 & 45 & 45 & 8 & 26 & 51 & 86 \\
\hline & & Cyperus aggregatus & 1 & 1 & 0,25 & 1 & 1 & 8 & 1 & 1 & 10 \\
\hline & & TOTAL & 173 & 12 & 3 & 173 & 87,5 & 100 & 100 & 100 & 300 \\
\hline & \multirow{11}{*}{400} & Kyllinga brevifolia & 9 & 1 & 0,25 & 9 & 9 & 8 & 5 & 9 & 21 \\
\hline & & Cleome aculeata & 3 & 2 & 0,5 & 3 & 1,5 & 15 & 2 & 1 & 19 \\
\hline & & Pennisetum purpereum & 10 & 1 & 0,25 & 10 & 10 & 8 & 6 & 9 & 23 \\
\hline & & Paspalum maritimum & 103 & 3 & 0,75 & 103 & 34,33 & 23 & 59 & 32 & 114 \\
\hline & & Spigela anthelia & 2 & 1 & 0,25 & 2 & 2 & 8 & 1 & 2 & 11 \\
\hline & & Coladium bicolor & 1 & 1 & 0,25 & 1 & 1 & 8 & 1 & 1 & 9 \\
\hline & & Eleusine indica & 1 & 1 & 0,25 & 1 & 1 & 8 & 1 & 1 & 9 \\
\hline & & Brachiaria ruziziensis & 1 & 1 & 0,25 & 1 & 1 & 8 & 1 & 1 & 9 \\
\hline & & Cyperus aggregatus & 4 & 1 & 0,25 & 4 & 4 & 8 & 2 & 4 & 14 \\
\hline & & Digitaria bicornis & 42 & 1 & 0,25 & 42 & 42 & 8 & 24 & 40 & 71 \\
\hline & & TOTAL & 176 & 13 & 3,25 & 176 & \multicolumn{2}{|c|}{105,83100} & 100 & 100 & 300 \\
\hline & \multirow{9}{*}{50} & Pennisetum purpereum & 20 & 1 & 0,25 & 20 & 20 & 9 & 10 & 13 & 33 \\
\hline & & Kyllinga odorata & 64 & 1 & 0,25 & 64 & 64 & 9 & 33 & 42 & 84 \\
\hline & & Paspalum maritimum & 38 & 2 & 0,5 & 38 & 19 & 18 & 20 & 12 & 50 \\
\hline & & Sebastiania corniculata & 1 & 1 & 0,25 & 1 & 1 & 9 & 1 & 1 & 10 \\
\hline & & Cleome aculeata & 6 & 2 & 0,5 & 6 & 3 & 18 & 3 & 2 & 23 \\
\hline & & Paspalum maritimum & 27 & 1 & 0,25 & 27 & 27 & 9 & 14 & 18 & 41 \\
\hline & & Eragrostis plana & 35 & 2 & 0,5 & 35 & 17,5 & 18 & 18 & 11 & 48 \\
\hline & & Emilia coccinea & 1 & 1 & 0,25 & 1 & 1 & 9 & 1 & 1 & 10 \\
\hline & & TOTAL & 192 & 11 & 2,75 & 192 & 152,5 & 100 & 100 & 100 & 300 \\
\hline & & Cleome aculeata & 2 & 2 & 0,5 & 2 & 1 & 22 & 2 & 1 & 25 \\
\hline & & Paspalum maritimum & 75 & 2 & 0,5 & 75 & 37,5 & 22 & 66 & 50 & 138 \\
\hline & & Cynodon dactylon & 4 & 1 & 0,25 & 4 & 4 & 11 & 4 & 5 & 20 \\
\hline
\end{tabular}




\begin{tabular}{|c|c|c|c|c|c|c|c|c|c|c|c|}
\hline \multirow{18}{*}{ Faixa } & & Pennisetum purpereum & 23 & 1 & 0,25 & 23 & 23 & 11 & 20 & 30 & 62 \\
\hline & & Croton lobatus & 1 & 1 & 0,25 & 1 & 1 & 11 & 1 & 1 & 13 \\
\hline & & Digitaria bicornis & 7 & 1 & 0,25 & 7 & 7 & 11 & 6 & 9 & 27 \\
\hline & & Spigelia anthelmia & 2 & 1 & 0,25 & 2 & 2 & 11 & 2 & 3 & 16 \\
\hline & & TOTAL & 114 & 9 & 2,25 & 114 & 75,5 & 100 & 100 & 100 & 300 \\
\hline & \multirow{7}{*}{200} & Paspalum maritimum & 159 & 3 & 0,75 & 159 & 53 & 27 & 57 & 35 & 119 \\
\hline & & Cynodon dactylon & 26 & 3 & 0,75 & 26 & 8,67 & 27 & 9 & 6 & 42 \\
\hline & & Pennisetum purpereum & 86 & 1 & 0,25 & 86 & 86 & 9 & 31 & 56 & 96 \\
\hline & & Kyllinga odorata & 1 & 1 & 0,25 & 1 & 1 & 9 & 0 & 1 & 10 \\
\hline & & Cleome aculeata & 6 & 2 & 0,5 & 6 & 3 & 18 & 2 & 2 & 22 \\
\hline & & Mimosa pudica & 1 & 1 & 0,25 & 1 & 1 & 9 & 0 & 1 & 10 \\
\hline & & TOTAL & 279 & 11 & 2,75 & 279 & \multicolumn{2}{|c|}{152,67100} & 100 & 100 & 300 \\
\hline & \multirow{6}{*}{400} & Paspalum maritimum & 184 & 4 & 1 & 184 & 46 & 40 & 91 & 77 & 208 \\
\hline & & Cyperus aggregatus & 8 & 3 & 0,75 & 8 & 2,67 & 30 & 4 & 4 & 38 \\
\hline & & Cyperus surinamensis & 2 & 1 & 0,25 & 2 & 2 & 10 & 1 & 3 & 14 \\
\hline & & Cleome aculeata & 8 & 1 & 0,25 & 8 & 8 & 10 & 4 & 13 & 27 \\
\hline & & Eragrostis plana & 1 & 1 & 0,25 & 1 & 1 & 10 & 0 & 2 & 12 \\
\hline & & TOTAL & 203 & 10 & 2,5 & 203 & 59,67 & 100 & 100 & 100 & 300 \\
\hline \multirow{28}{*}{ Localizada } & \multirow{7}{*}{50} & Cyperus distans & 1 & 1 & 0,25 & 1 & 1 & 10 & 1 & 2 & 13 \\
\hline & & Paspalum maritimum & 159 & 4 & 1 & 159 & 39,75 & 40 & 94 & 81 & 214 \\
\hline & & Cleome aculeata & 3 & 2 & 0,5 & 3 & 1,5 & 20 & 2 & 3 & 25 \\
\hline & & Pennisetum purpereum & 2 & 1 & 0,25 & 2 & 2 & 10 & 1 & 4 & 15 \\
\hline & & Cyperus aggregatus & 1 & 1 & 0,25 & 1 & 1 & 10 & 1 & 2 & 13 \\
\hline & & Cyperus surinamensis & 4 & 1 & 0,25 & 4 & 4 & 10 & 2 & 8 & 20 \\
\hline & & TOTAL & 170 & 10 & 2,5 & 170 & 49,25 & 100 & 100 & 100 & 300 \\
\hline & \multirow{8}{*}{100} & Paspalum maritimum & 86 & 3 & 0.75 & 86 & 28.67 & 27 & 57 & 44 & 128 \\
\hline & & Cleome aculeata & 45 & 3 & 0.75 & 45 & 15 & 27 & 30 & 23 & 80 \\
\hline & & Cyperus flavus & 1 & 1 & 0.25 & 1 & 1 & 9 & 1 & 2 & 11 \\
\hline & & Sebastiania corniculata & 1 & 1 & 0.25 & 1 & 1 & 9 & 1 & 2 & 11 \\
\hline & & Emilia coccinea & 1 & 1 & 0.25 & 1 & 1 & 9 & 1 & 2 & 11 \\
\hline & & Cyanthilium cinereum & 1 & 1 & 0.25 & 1 & 1 & 9 & 1 & 2 & 11 \\
\hline & & Cyperus aggregatus & 17 & 1 & 0.25 & 17 & 17 & 9 & 11 & 26 & 47 \\
\hline & & TOTAL & 152 & 11 & 2.75 & 152 & 64,67 & 100 & 100 & 100 & 300 \\
\hline & \multirow{6}{*}{200} & Cynodon dactylon & 4 & 1 & 0,25 & 4 & 4 & 11 & 2 & 5 & 19 \\
\hline & & Paspalum maritimum & 133 & 3 & 0,75 & 133 & 44,33 & 33 & 79 & 61 & 173 \\
\hline & & Pennisetum purpereum & 18 & 1 & 0,25 & 18 & 18 & 11 & 11 & 25 & 47 \\
\hline & & Cleome aculeata & 11 & 2 & 0,5 & 11 & 5,5 & 22 & 7 & 8 & 36 \\
\hline & & Cyperus aggregatus & 2 & 2 & 0,5 & 2 & 1 & 22 & 1 & 1 & 25 \\
\hline & & TOTAL & 168 & 9 & 2,25 & 168 & 72,83 & 100 & 100 & 100 & 300 \\
\hline & \multirow{7}{*}{400} & Eragrostis plana & 5 & 2 & 0,5 & 5 & 2,5 & 18 & 4 & 6 & 28 \\
\hline & & Paspalum maritimum & 119 & 4 & 1 & 119 & 29,75 & 36 & 84 & 70 & 190 \\
\hline & & Cleome aculeata & 13 & 2 & 0,5 & 13 & 6,5 & 18 & 9 & 15 & 43 \\
\hline & & Cyperus flavus & 1 & 1 & 0,25 & 1 & 1 & 9 & 1 & 2 & 12 \\
\hline & & Cyperus distans & 1 & 1 & 0,25 & 1 & 1 & 9 & 1 & 2 & 12 \\
\hline & & Kyllinga brevifolia & 2 & 1 & 0,25 & 2 & 2 & 9 & 1 & 5 & 15 \\
\hline & & TOTAL & 141 & 11 & 2,75 & 141 & 42,75 & 100 & 100 & 100 & 300 \\
\hline \multirow{7}{*}{ Testemunha } & \multirow{7}{*}{0} & Paspalum maritimum & 92 & 3 & 0.75 & 92 & 30.67 & 27 & 56 & 32 & 116 \\
\hline & & Penicetum purpurium & 10 & 1 & 0.25 & 10 & 10.00 & 9 & 6 & 10 & 26 \\
\hline & & Cleome aculeata & 8 & 3 & 0.75 & 8 & 2.67 & 27 & 5 & 3 & 35 \\
\hline & & Desmodium uncinatum & 4 & 1 & 0.25 & 4 & 4.00 & 9 & 2 & 4 & 16 \\
\hline & & Cyperus distans & 6 & 1 & 0.25 & 6 & 6.00 & 9 & 4 & 6 & 19 \\
\hline & & Eragrostis plana & 42 & 1 & 0.25 & 42 & 42.00 & 9 & 26 & 44 & 78 \\
\hline & & TOTAL & 162 & 10 & 2.50 & 162 & 95.33 & 100 & 100 & 100 & 300 \\
\hline
\end{tabular}


Os modos de aplicação em área total com volume de calda de $50 \mathrm{~L} \mathrm{ha}^{-1}$ e localizada com volume de calda de $50 \mathrm{~L} \mathrm{ha}^{-1}$, promoveu uma menor diversidade de espécies de plantas daninhas em comparação ao restante dos modos de aplicação (tabela 5), incluído a testemunha. Ou seja, um menor volume de calda proporciona uma menor cobertura do alvo. Diante disto há uma menor disponibilidade de Trichoderma sp. para as plantas daninhas.

Paspalum maritimum e Cleoma aculeata foram as espécies que estiveram presente em todos os tratamentos (Tabela 5). Com destaque para a aplicação em faixa com volume de calda de $200 \mathrm{~L} \mathrm{ha}^{-1}$ e localizada com volume de calda de $50 \mathrm{~L} \mathrm{ha}^{-1}$. Paspalum maritimum foi a espécie que teve o maior IVI. [28] relata que o capim-gengibre (Paspalum maritimum) é uma das espécies que se notabilizam pela alta capacidade de invadir as áreas de pastagens cultivadas, formando verdadeiras colônias puras dominando a pastagem em poucos anos.

Não há diferença entre os volumes de calda e os tipos de aplicação de Trichoderma sp. para: densidade, frequência, abundância de plantas daninhas em comparação a testemunha sem capina (Figura 3). No entanto ao avaliar a produção de massa seca, houve diferença entre os modos de aplicação com diferentes volumes de calda, no qual a aplicação em área total com volume de calda de $50 \mathrm{~L} \mathrm{ha}^{-1}$ e aplicação localizada com volume de calda de $400 \mathrm{~L} \mathrm{ha}^{-1}$ promoverem uma menor quantidade de massa seca, quando equiparado a aplicação em área total com volume de calda de $200 \mathrm{~L}$ $\mathrm{ha}^{-1}$ e testemunha. Logo, a hipótese de que Trichoderma sp. aumenta a incidência de plantas daninhas, não é aceita. No entanto, é necessário o estudo em uma maior diversidade de áreas e épocas do ano, para uma conclusão de maior confiança.

\section{RESPOSTA AO VOLUME DE CALDA.}

Observou-se crescimento linear na densidade de plantas daninhas com o incremento no volume de calda quando utilizado a aplicação em área total (Figura 4). Este fato posivelmente foi proporcionado por uma maior dispersão de gotas em aplicação em área total e uma maior cobertura das plantas daninhas com o maior volume de calda e assim maior dispersão do microrganismo na linha e entrelinha da cultura, favorecendo maior disponibilidade de inoculação de Trichoderma sp. nas plantas daninhas, as quais podem ter se favorecido da promoção de crescimento. [12], observaram maior cobertura do alvo e maior eficiência de controle de Spodoptera frugiperda em milho com o aumento do volume de calda.

Logo, se for escolhido a aplicação em área total de Trichoderma sp., é melhor indicado um volume de calda menor para que não ocorra maior densidade de plantas daninhas (Figura 4). No entanto, o menor volume de calda pode reduzir a possibilidade de viabilidade do microrganismo para a cultura, já que a coberturado alvo será menor.

Quando utilizado aplicação em faixa, há comportamento de crescimento quadrático da densidade (Figura 4). Anali-
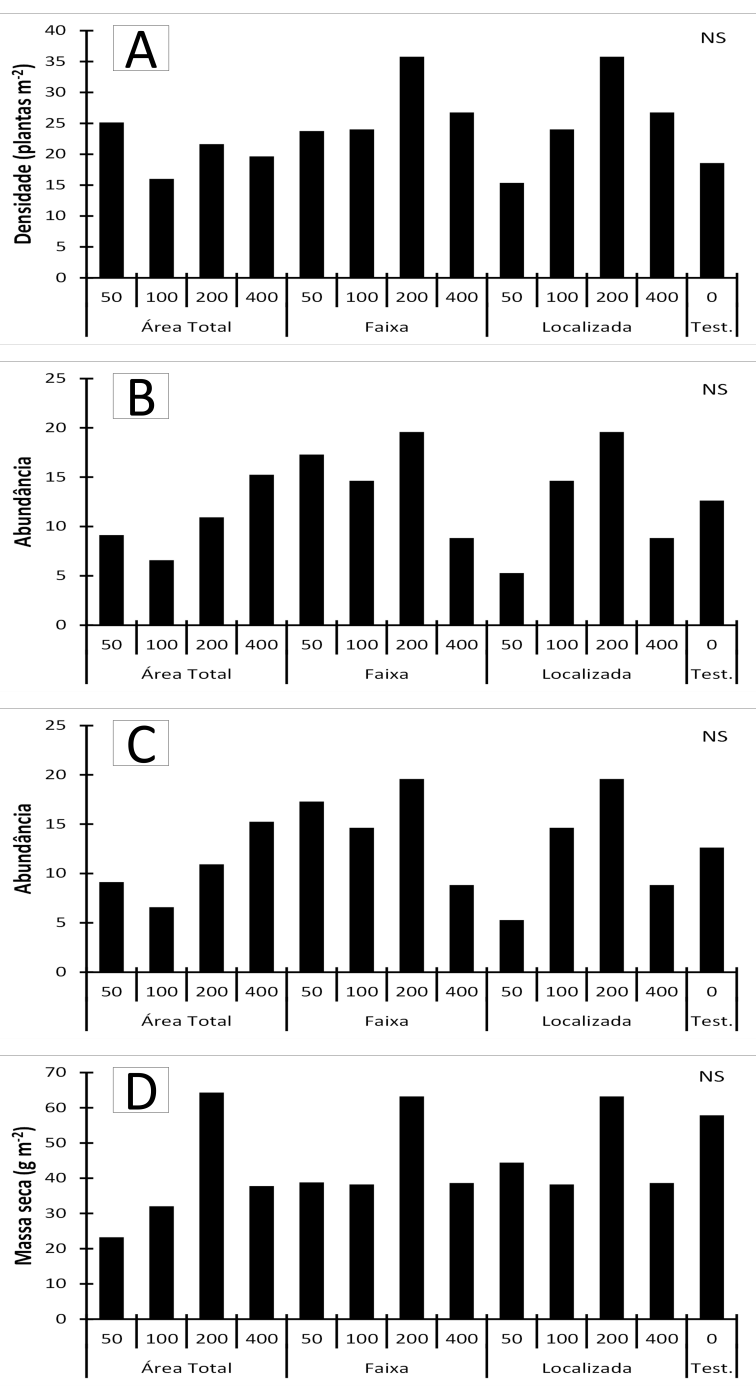

Figura 3. Densidade (A), abundância (B), frequência (C) e massa seca (D) de plantas daninhas em diferentes volumes $(50 ; 100 ; 200 ; 400 \mathrm{~L}$ ha-1) de calda e tipos de aplicação de Trichoderma sp. NS: não significativo a $5 \%$ de probabilidade pelo teste $\mathrm{F}$.

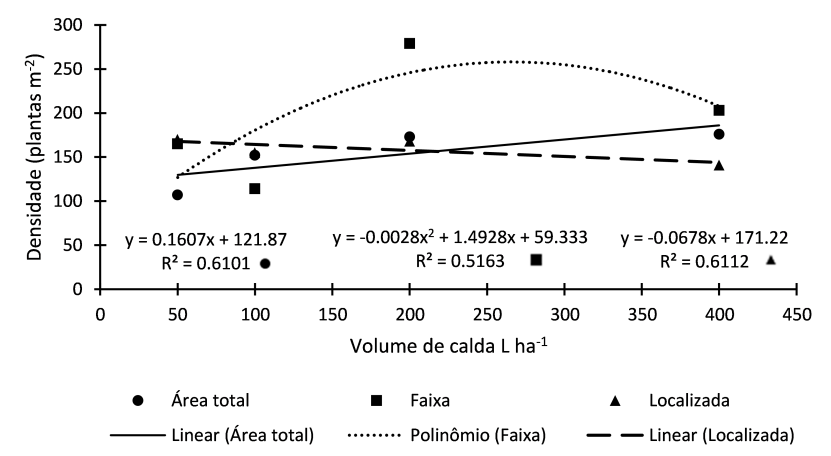

Figura 4. Densidade de plantas daninhas em função do volume de calda para aplicação de Trichoderma sp. na cultura da mandioca. Fonte: autor

sando o método de aplicação conforme verificado na Figura 2 (B), observa-se que apesar de ocorrer menor dispersão de 
gotas na área, há uma maior concentração de calda na linha de plantio e dessa maneira pode ter ocorrido uma maior disponibilidade de esporos para as plantas daninhas favorecendo um aumento na densidade populacional de plantas daninhas. O volume de calda de $260,5 \mathrm{~L} \mathrm{ha}^{-1}$ foi o ponto máximo de densidade com aplicação em faixa, dessa maneira o volume de calda de $50 \mathrm{~L} \mathrm{ha}^{-1}$ apresentou a menor densidade e deve ser utilizado se for usado a aplicação em faixa visando menor problema com as plantas daninhas.

A aplicação localizada teve leve redução na densidade de plantas daninhas com o aumento no volume de calda (Figura 4). Observa-se, que neste tipo de aplicação não há formação de gotas, e sim o lançamento sólido de seis jatos contínuos de maneira localizada ao redor da planta reduzindo grandemente a cobertura pulverizada e dessa maneira reduzindo o acesso das plantas daninhas ao microrganismo aplicado. Há no entanto, a menor possibilidade de inoculação da cultura, sendo necessário avaliar a efetiva ação do microrganismo na planta.

Não há efeito significativo na frequência de plantas daninhas em qualquer tipo de aplicação de Trichoderma sp. (Figura 5), sendo portanto um fator que não influencia a distribuição espacial das plantas daninhas de acordo com as espécies do local.

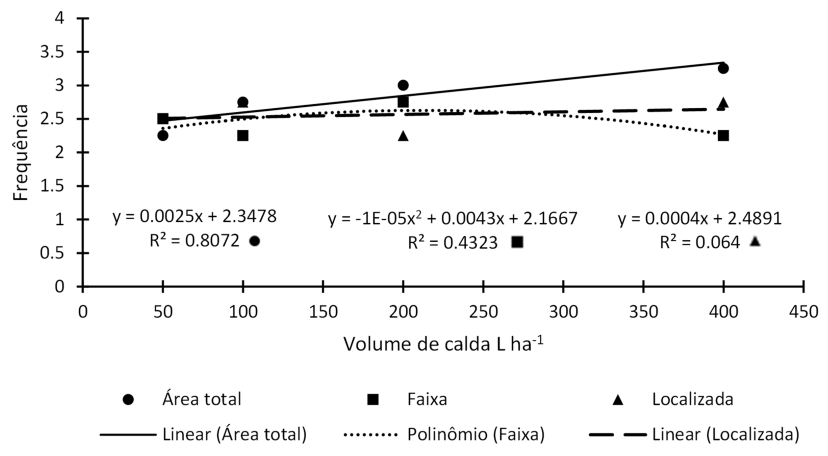

Figura 5. Frequência de plantas daninhas em função do volume de calda para aplicação de Trichoderma sp. na cultura da mandioca.

Já a abundância de plantas daninhas cresceu de maneira linear quando realizado aplicação em área total quando em comparação a aplicação em faixa e localizada (Figura 6), os quais tiveram decréscimo com o incremento no volume de calda. A abundância de plantas está relacionada a concentração de plantas daninhas em determinado local, fato que dificulta o manejo de plantas daninhas. Portanto para aplicação em área total é indicado o menor volume de calda para reduzir a abundância de plantas daninhas e na aplicação em faixa e localizada indica-se maior volume de calda.

Em todos os métodos de aplicação houve comportamento quadrático (Figura 7) de massa seca de parte aérea sendo obtido ponto máximo de massa seca de parte aérea de: 247,3 $\mathrm{L} \mathrm{ha}^{-1}$ para aplicação em área total; $238,15 \mathrm{~L} \mathrm{ha}^{-1}$ para aplicação em área faixa e $172,8 \mathrm{~L} \mathrm{ha}^{-1}$ para aplicação em localizada. Ainda que não se possa provar a causa da

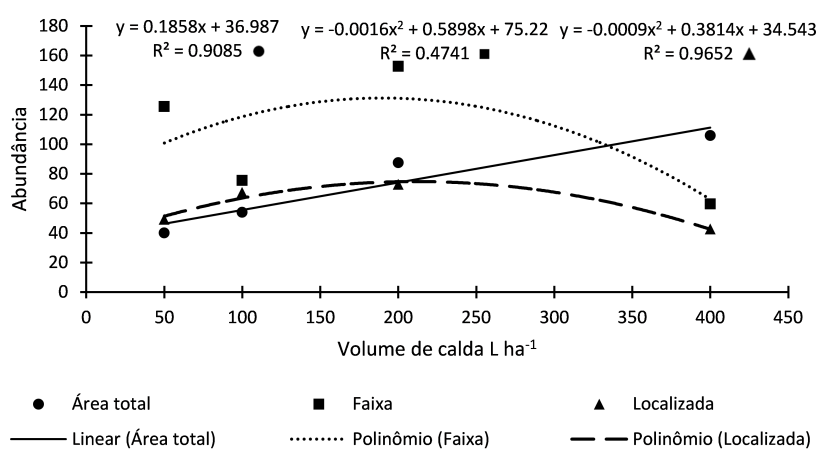

Figura 6. Abundância de plantas daninhas em função do volume de calda para aplicação de Trichoderma sp. na cultura da mandioca. Fonte: autor.

resposta, podemos aventar de que uma menor massa seca de parte aérea em menor volume de calda se deve a menor cobertura do alvo e menor disponibilidade para as plantas daninhas se beneficiarem da promoção de crescimento e possível efeito deletério em volume de calda maior devido a melhor inoculação da cultura, a qual pode ter favorecido crescimento de parte aérea e dessa maneira reduzindo a disponibilidade de luz na área de plantio.

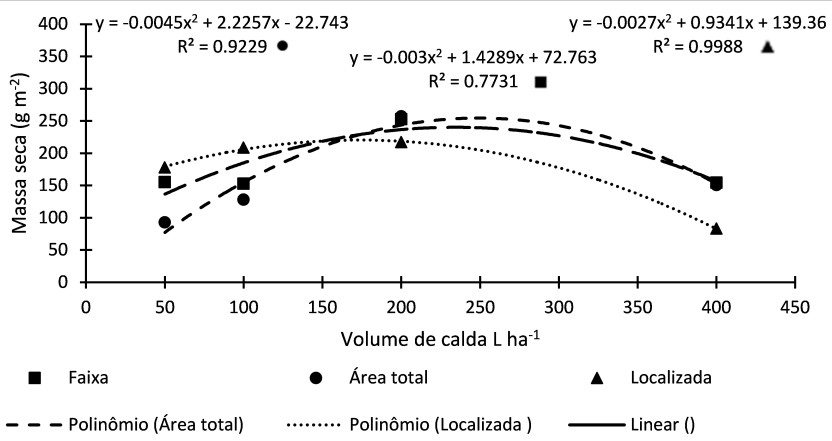

Figura 7. Massa seca de parte aérea de plantas daninhas em função do volume de calda para aplicação de Trichoderma sp. na cultura da mandioca.

\section{CONCLUSÃO}

Trichoderma sp. muda a dinâmica de plantas daninhas na cultura da mandioca. Há influência do tipo de aplicação e volume de calda nos parâmetros fitossociológicos de plantas daninhas e massa seca. Menor volume de calda com Trichoderma sp. reduz a densidade, abundância e massa seca de parte aérea de plantas daninhas para aplicação em área total. Maior volume de calda proporciona menor densidade, abundância e massa seca de parte aérea de plantas daninhas para aplicação em faixa e localizada. Volume de calda não interfere na frequência de plantas daninhas independente do tipo de aplicação.

\section{Referências}

[1] Alburquerque, J. A. A.; SEDIYAMA, T.; Silva, A. A.; CARNEIRO, J. E. S.; CECON, P. R.; ALVES, J. M. A. Interferência de plantas daninhas sobre a produtividade da mandioca (Manihot esculenta). Planta Daninha, Viçosa, v. 26, n. 2, p. 279-289. 2008. 
[2] ALbUQUERQUE, T.T.O.; MIRANDA, L.C.G.; SALIM, J.; TELES, F.F.F.; QUIRINO, J.G. Composição centesimal da raiz de 10 variedades de mandioca (Manihot esculenta Crantz) cultivadas em Minas Gerais. Revista Brasileira da Mandioca, v.12, n.1, p.7-12, jan. 1993.

[3] ALVES, A. A. C. Fisiologia da mandioca. Cruz das Almas: EMBRAPACNPMF, 1990.

[4] ANTUNIASSI, U. R. et al. Tecnologia de aplicação de defensivos. In: VARGAS, L. Manual de manejo e controle de plantas daninhas. Passo Fundo: Embrapa Trigo, 2008. p. 174-175.

[5] AZEVÊDO, C. L. L.; CARVALHO, J. E. B. de.; LOPES, L. C.; ARAÚJO, A. M. de A. Levantamento de plantas daninhas na cultura da mandioca, em um ecossistema semi-árido do Estado da Bahia. Magistra, v. 12, n. 1/2, 2000.

[6] BFG (The Brazil Flora Group), 2015. Growing knowledge: an overview of Seed Plant diversity in Brazil. Rodriguésia 66(4): 1085-1113. Doi: 10.1590/2175- 7860201566411.

[7] BOER, C.A.; ASSIS, R.L.; SILVA, G.P.; BRAZ, A.J.B.P.; BARROSO, A.L.L.; CARGNELUTTI FILHO, A.; PIRES, F.R. Biomassa, decomposição e cobertura do solo ocasionada por resíduos culturais de três espécies vegetais na região Centro Oeste do Brasil. Revista Brasileira de Ciência do Solo, v.32, p.843 851, 2008. DOI: 10.1590/S0100-06832008000200038.

[8] CALVO, C. L.; FOLONI, J. S. S.; BRANCALIÃO, S. B. Produtividade de fitomassa e relação c/n de monocultivos e consórcios de guandu-anão, milheto e sorgo em três épocas de corte. Bragantia, Campinas, v.69, n.1, p.77-86, 2010.

[9] CARVAlHO, J. E. B. Plantas daninhas e seu controle. In: MATTOS, P. L. P.; GOMES, J. C. (Coords.). O cultivo da mandioca. Cruz das Almas: Embrapa Mandioca e Fruticultura, 2000. p. 42-52.

[10] CLIMATE-DATA.ORG. Dados climáticos para cidades mundiais. Castanhal Clima (Brasil), 2019. Disponível em: $<$ https://pt.climatedata.org/america-do-sul/brasil/para/castanhal-26632/>.

[11] COSTA, A.G.F. Efeito da intensidade do vento, da pressão e de pontas de pulverização na deriva de aplicações de herbicidas em pré-emergência. Planta Daninha, v.25, n.1, p.203-210, 2007. Acesso em: 23 jan. 2019. doi: 10.1590/S0006-87052010000100029.

[12] CUNHA, P. A. R. J.; JÚNIOR, D. S. A. Volumes de calda e pontas de pulverização no controle químico de Spodoptera frugiperda na cultura do sorgo forrageiro. Eng. Agríc., Jaboticabal, v.30, n.4, p.692-699, jul./ago. 2010.

[13] FAO, Dados da produção mundial da mandioca. Disponível em: $<$ http://www.fao.org/faostat/es/data/QC $>$. Acesso em 12 jan. 2019.

[14] FREITAS, F. C. O. Nematóides das galhas, Meloidogyne spp., associados ao parasitismo de plantas na região amazônica. I - No Estado do Pará. Acta Amazônica 6(4): 405-408. 1976.

[15] FREITAS, S.P; RODRIGUES, J.C. e SILVA; Manejo de plantas daninhas no plantio direto da soja (glycine max) sobre o milheto (Pennisetum maximum). Planta Daninha, Viçosa-MG, v. 24, n. 3, p. 481-487, 2006.

[16] GONÇALVES, G. S.; ANDRADE, L. A.; XAVIER, K. R. F.; OLIVEIRA, L. S. B.; MOURA, M. P. Estudo do banco de sementes do solo em uma área de caatinga invadida por Parkinsonia aculeata L. R. bras. Bioci., Porto Alegre, v. 9, n. 4, p. 428-436, out./dez. 2011.

[17] INSTITUTO BRASILEIRO DE GEOGRAFIA E ESTATÍSTICA - IBGE. Levantamento sistemático da produção agrícola. Disponível em: Acesso em: 06 de fev. 2019.

[18] JAKELAITIS, A. et al. Efeitos de sistemas de manejo sobre a população de tiririca. Planta Daninha, v. 21, n. 01, p. 89- 95, 2003 b.

[19] MACHADO, D.F.M.; PARZIANELLO, F.R.; SILVA, A.C.F. E ANTONIOLLI, Z.I. (2009) - Trichoderma no Brasil: O fungo e o bioagente. Revista de Ciências Agrárias, vol. 35, n. 1, p. 274-288.

[20] MARQUES, L.J.P; SILVA, M.R.M; LOPES, G.S; CORRÊA, M.J.P; ARAUJO, M.S; COSTA, E.A; MUNIZ, F.H. Dinâmica de populações e fitossociologia de plantas daninhas no cultivo do feijão-caupi e mandioca no sistema corte e queima com o uso de arado. Planta Daninha, ViçosaMG, v. 29, p. 981-989, 2011. Número Especial.

[21] MASSOLA, N. S.; BEDENDO, I. P. 2005. Doenças da Mandioca. In: Kimati, H., Amorim, L., Rezende, J.A.M., Bergamin Filho, A., Camargo, L.E.A. (Eds.). Manual de Fitopatologia: Doenças das Plantas Cultivadas. $4^{\text {a }}$. Ed. São Paulo: Ceres. v.2, pp. 449-455.

[22] MATTOS, P. L. P.; CARDOSO, E. M. R. Plantas daninhas. Disponível em: $<$ http:// sistemasdeproduçao.cnptia.embrapa.br>. Acesso em: 22 de ago. de 2005.

[23] MATUO, T. Técnicas de aplicação de defensivos agrícolas. Jaboticabal: FUNEP, 1990
[24] MONTALVÃO, S. C. L. Potencial de Trichoderma spp. no biocontrole de doenças de tomateiro. 71p. Dissertação (mestrado em fitopatologia) programa de pós graduação em Fitopatologia, universidade de Brasília, Distrito Federal, 2012.

[25] MUELLER-DOMBOIS, D.; ELLENBERG, H. A. Aims and methods of vegetation ecology. New York: John Wiley, 1974. 547 p.

[26] OLIVEIRA, A. R.; FREITAS, S. P. Levantamento fitossociológico de plantas daninhas em áreas de produção de cana-de-açúcar. Planta Daninha, v. 26, n. 1, p. 33-46, 2008. Disponível em: . doi: 10.1590/S010083582008000100004 .

[27] OTSUBO, A. A. LORENZI, J. O. Cultivo da Mandioca na Região CentroSul do Brasil. Dourados, MS 2002. EMBRAPA - 2002.

[28] SOUZA FILHO, A.P.S. Interferência potencialmente alelopática do capim-gengibre (paspalum maritimum) em áreas de pastagens cultivadas. Planta Daninha, Viçosa-MG, v. 24, n. 3, p. 451-456, 2006.

[29] STEFANELLO, L. Produtividade e controle de podridão radicular na cultura da mandioca (Manihot esculenta) com o uso de Trichoderma spp. 64 p. Dissertação (mestrado em produção vegetal) - programa de pós graduação em Agronomia, Universidade Estadual do Oeste do Paraná, Paraná, 2016.

[30] TAKAHASHI, M.; GONÇALO, S. A cultura da mandioca. Paranavaí: s.n., 2001, $88 \mathrm{p}$

[31] VIANA, R.G. Deposição de gotas no dossel da soja por diferentes pontas de pulverização hidráulica e pressões de trabalho. Engenharia na Agricultura, v.16, n.4, p.428- 435, 2008. Disponível em. Acesso em: 23 jan. 2019.

[32] WOLLUM II, A. G. Cultural methods for soil microorganisms. In: MILLER, R. H.; KEENEY, D. R. Methods of soil analysis: chemical and microbiological properties. Madison: Soil Science of American. 1982.

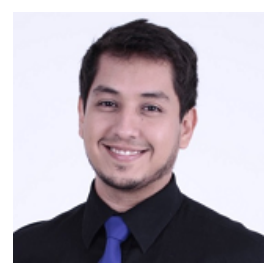

ITALLO MICHAEL SOARES LEAL

Graduação em Tecnologia de Alimentos pela Universidade do Estado do Pará (2014) e Agronomia pela Universidade Federal Rural da Amazônia (2019), foi bolsista de Programa de Educação Tutorial PET- AGRONOMIA (2017-2019), trabalhando com Ensino, Pesquisa e Extensão, e Bolsista de Desenvolvimento Tecnológico e Industrial no Instituto Tecnológico Vale - ITVDS (2019-

2020). Atualmente é Consultor Ambiental onde desenvolve projetos de Licenciamento Ambiental de empreendimentos Agrossilvipastoris.

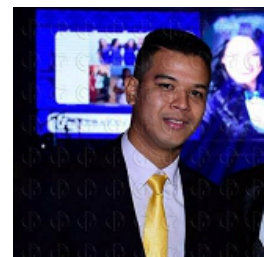

LEANDRO DO ROSARIO SILVA

Engenheiro Agrônomo pela Universidade Federal Rural da Amazônia, egresso do Programa de Educação Tutorial em Agronomia da mesma universidade, sócio e diretor da empresa LB Projetos e Soluções Agropecuária LTDA. 


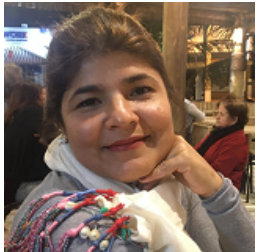

GISELE BARATA DA SILVA

Graduada em Agronomia pela Universidade Federal Rural da Amazônia (1998), mestrado em Agronomia pela Universidade Federal de Goiás (2000) e doutorado em Agronomia (Fitopatologia) pela Universidade Federal de Viçosa (2004). Professora associada II da UFRA, foi vice-coordenadora do Programa de pós-graduação em agronomiaPgAgro (2010-2017), é atualmente é coordenadora do PgAgro. Ministra as disciplinas microbiologia, controle biológico e patogênese.Tem experiência na área de Agronomia, com ênfase em bioestimulantes e supressores de doenças em palmeiras tropicais e gramíneas.

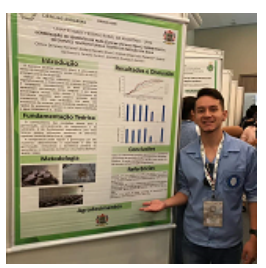

GABRIEL DAMASCENO FERREIRA CUNHA Graduando em Agronomia na Universidade Federal Rural da Amazônia, bolsista do grupo PET Agronomia.

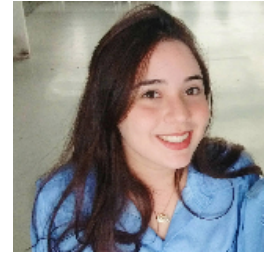

ANA CLARA MOURA DE SOUSA

Acadêmica de Agronomia na Universidade Federal Rural da Amazônia/UFRA (2017-até o momento), Estágio voluntário no Programa de Educação Tutorial PET-Agronomia/UFRA (2018-2019), Monitora de Fisiologia Vegetal no Programa Institucional de Bolsa de Iniciação à Docência- PIBID/UFRA (2018-2019), Bolsista no Programa Institucional de Bolsas de Iniciação Científica PIBIC/Ufra na área de Fisiologia Vegetal (2019-até o momento), Estagiária no Grupo de Pesquisa Estudos da Biodiversidade de Plantas Superiores EBPS/UFRA (2019-até o momento).

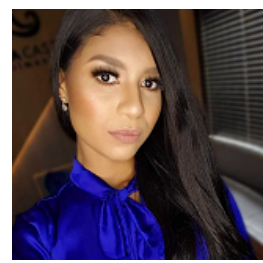

\section{ANA CAROLINA MELO RIBEIRO}

Mestranda em Genética e Melhoramento de Plantas na Universidade Estadual do Norte Fluminense Darcy Ribeiro, atuando na área de Melhoramento Genético de Plantas. Engenheira Agrônoma pela Universidade Federal Rural da Amazônia - Campus Belém. Foi bolsista do Programa de Educação Tutorial PET Agronomia (PETAgronomia/SeSu/MEC). Foi estagiária do Laboratório de Recursos Genéticos e Biotecnologia da Empresa Brasileira de Pesquisa Agropecuária (EMBRAPA Amazônia Oriental). Técnica em Secretariado - EEETEPA Anísio Teixeira.

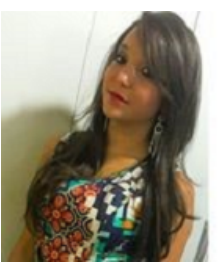

\section{ALEXANDRA MONTEIRO ALVES}

Graduanda em Agronomia na Universidade Federal Rural da Amazônia.

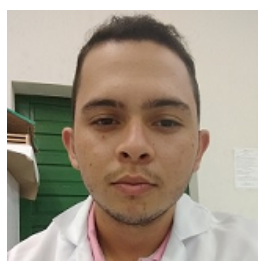

\section{GABRIEL DA SILVA VASCONCELOS}

Graduando em Agronomia na Universidade Federal Rural da Amazônia, bolsista do grupo PET Agronomia.

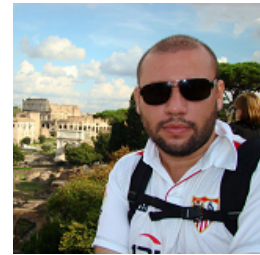

\section{RAFAEL GOMES VIANA}

Engenheiro Agrônomo graduado na Universidade Federal Rural da Amazônia (2003), Mestre (2006) e Doutor em Fitotecnia na Universidade Federal de Viçosa (2010) com período sanduíche em Fitossanidade na Universitat de Lleida-Espanha. Atualmente é professor Associado I da Universidade Federal Rural da Amazônia no Campus de Belém, tutor do grupo PET Agronomia e pesquisador líder do grupo de pesquisa Manejo Integrado de Plantas Daninhas na Amazônia (MIPDAM). 